\title{
Effects of nursing record education focused on legal aspects at small and medium sized hospitals"
}

\author{
Do, Taehee ${ }^{1)}$ (D) Kim, Heejung ${ }^{2)}(\mathbb{D}$ \\ 1) Graduate student, Daegu Catholic University \\ 2) Associate Professor, College of Nursing.Institute of Nursing Science, Daegu Catholic University
}

Purpose: The purpose of this study was to examine the effect of nursing record education on the knowledge and performance of nursing record of nurses at small- and medium-sized hospitals. Methods: The participants were 62 nurses working in two small- and medium-sized hospitals. Thirty-two nurses comprised the experimental group, and 30 nurses comprised the control group. Nursing record education was provided for the experimental group. Data were analyzed by $\mathrm{x}^{2}$-test and $\mathrm{t}$-test analysis using the IBM SPSS statistics 25.0 Program. Results: After education, the knowledge ( $\mathrm{t}=2.43, p=.019)$, performance ( $\mathrm{t}=2.19$, $p=.033)$ and behavior scores $(\mathrm{t}=2.42, p=.018)$ on nursing record were significantly higher in the experimental group than in the control group. Based on this result, nursing record education is an effective intervention to improve nurses' knowledge and performance in writing nursing records in small- and medium-sized hospitals. Conclusion: We suggest the development of a systematic and standardized education program on nursing record including its legal aspects, for nurses in small- and medium-sized hospitals. The results of this study can be used as basic data for developing a nursing record education program for small- and medium-sized hospitals.

Keywords: Behavior, Education, Knowledge, Nurses, Nursing records

\section{Introduction}

Nursing records provide an account of the care and treatment given to a patient, providing a way to monitor progress and develop clinical histories. They allow for continuity of care by facilitating treatment and support [1]. They are an official communication tool for medical staff and an integral part of patient care, providing evidence of care for patients [2]. Nursing records are also used as basic data for healthcare policymaking, statistical analysis, research, education, and insurance claims [3]. Therefore, nurses are responsible for maintaining accurate records of the care they provide and are accountable if information is incomplete and inaccurate [4].

As electronic medical records are becoming more widely used, nursing records are also transitioning from paper to electronic formats. The expansion of electronic nursing records (ENRs) promotes better quality, completeness, and accuracy. Furthermore, electronic nursing records have allowed nurses to spend more time nursing patients since less time is required to write nursing records [2]. On the other hand, a study criticized that ENRs often fail to reflect individual patients' personal nursing care because the records contain repetitive, standardized text. This threatens patient safety, revealing the negative side of ENRs $[2,5]$. Lee [6] reported that nursing records' accuracy in ENRs was only $61.9 \%$. Kang [7] found that while $94.9 \%$ of ENRs contained information about patients' conditions and status, only $65.3 \%$ recorded nursing services provided to patients.

The obstacles to writing nursing records are having several

Keywords: Behavior, Education, Knowledge, Nurses, Nursing records

Address reprint requests to: Kim, Heejung

College of Nursing, Daegu Catholic University, 33 Duryugongwon-ro 17-gil, Nam-gu, Daegu, 42472, Republic of Korea

Tel: +82-53-650-4830 Fax: +82-53-650-4392 E-mail: cholong98@cu.ac.kr

* This manuscript was adapted from a master's thesis by Taehee Do from Daegu Catholic University in Daegu, Korea

Received: March 11, 2021 Revised: May 6, 2021 Accepted: May 7, 2021

This is an open access article distributed under the terms of the Creative Commons Attribution Non-Commercial License (http://creativecommons.org/licenses/by-nc/4.0), which permits unrestricted non-commercial use, distribution, and reproduction in any medium, provided the original work is properly cited. 
patients to care for and excessive workload. Nurses generally tend to neglect writing nursing records as they prioritize providing direct nursing care [6,8]. A study identified that obstacles to writing nursing records were lack of knowledge about nursing record, lack of awareness on the importance of nursing records, and difficulty in describing patients' internal conditions [9]. Medical staff cannot communicate effectively without proper nursing records, and poor communication can negatively affect patient care. Therefore, nurses must ensure that their documentation meets high standards and must record treatment decisions and plans, nursing services provided, and patient's response to treatment $[10,11]$.

Nurses vary in their level of knowledge about nursing records. However, systemic education on nursing record for nurse has been insufficient [12]. Nursing students receive theoretical education at college, with little hands-on instruction; most of nurses learn only how to use their hospitals' ENR system during orientation in South Korea [13]. Only $15.8 \%$ of clinical nurses in South Korea receive nursing-record education at hospital and do not receive sufficient hands-on or in-service training. Especially, fewer still receive sufficient education on the legal aspects of nursing records despite the educational demand for it was increasing [14].

Record keeping is an essential part of nursing practice with clinical and legal significance [4]. The importance of nursing records as legal documents is growing. The number of medical disputes increased by $67 \%$ on average from 2015 to 2019 [15]. Accordingly, the number of nursing-related medical disputes has also increased with the expanding roles and responsibilities of nurses. Therefore, it is imperative that nurses recognize and respond to nursing errors, understand their legal obligations and responsibilities, and keep complete and accurate records of all nursing activities.

In 2016, 34.2\% of all nurses in South Korea worked in small or medium hospitals [16]. The incidence of medical disputes in small and medium hospitals was $54.1 \%$, twice the incidence in tertiary hospitals (19.7\%) [17]. However, the nursing record performance of nurses in small and medium hospitals was lower than in tertiary hospitals [17]. Despite the higher educational need of nurses in small and medium hospitals with regard to nursing records than those in large hospitals, education for nurses in small and medium hospitals is not efficiently provided due to the lack of dedicated educators [18]. Therefore, nursing record education focused legal aspect is essential to ensure better quality of nursing care and protect nurses from legal disputes.

Most studies on nursing record have been conducted on nurses in large hospitals. While several studies have measured nurses' level of knowledge on nursing records [12,13], a little research has been done on effects of nursing record education with nurses, especially education programs focused on the legal aspects of nursing records in small and medium hospitals [14,19]. This study examined the effects of a nursing-record education program focused on the legal aspect of nursing record among nurses in small and medium hospitals in South Korea and aimed to provide basic data to develop nursing-record education program.

\section{Methods}

\section{Research Design}

A prospective quasi-experimental nonequivalent control group pretest-posttest design was used for this study. The study was conducted to investigate the effect of nursing record education on the nursing-record knowledge and performance among nurses in small- and medium-sized hospitals.

\section{Participants}

The participants were nurses who have worked for at least six months in two small or medium hospitals in D City, South Korea. The hospitals had passed the Hospital Accreditation Program and used ENR systems. The inclusion criteria for selecting participants were (1) a staff nurse worked for at least six months in small or medium hospitals, (2) being willing to participate in this study, (3) understanding the purpose of the study, and agreeing to participate. Outpatient nurses and head nurses were excluded. The sample size for this study was calculated for an independent t-test at a significance level of $p<$ .05 , with an effect size of 0.8 and power of $1-\beta=0.85$ by Cohen's $d$ in the previous study [14]. The required sample size was calculated using the G*Power software (version 3.1.9.2, Heinrich Heine University, Dusseldorf, Germany), resulting in 30 participants in each group [20]. The expected loss to follow-up was taken as $20 \%$, and the final sample size was 36 for each group and seventy-two nurses were included. Nurses were randomly assigned to a group through coin tossing. A nurse was assigned to the experimental group if the coin turned up heads 
and in the control group if the coin turned up tails. Of the seventy-two nurses, eight were excluded due to incomplete answers and two resigned or changed departments. Therefore, thirty-two in the experimental group and thirty in the control group completed.

\section{Outcome Measurements}

- Knowledge about nursing records

A nursing record knowledge evaluation tool developed by Kim \& Park [21] was used to measure the level of knowledge of nursing records among nurses. Their questionnaire comprised 65 questions on the Do's (39 items) and Don'ts (26 items) of writing nursing records, covering issues of anonymity, exactness, truthfulness, staff conflicts, privacy, communication, and malpractice. The respondents answered either yes or no and scores 1 point for a correct answer, and 0 for incorrect answer. Each item adds up to the total score and the score ranges from 0 to 65 . Higher total scores indicate a higher knowledge level. The Cronbach's a was .73 in Kim \& Park's study [21] and KR-20 was .79 in this study.

\section{- Nursing record performance}

We assessed nursing record performance using the nursing record performance evaluation tool of Kim's [22] study. Since the tool was initially developed for nurses in large hospitals, we revised it for small and medium hospitals. No major revision was required. Our revisions were reviewed by two nursing professors, two directors of nursing department, and two head nurses with over ten years of experience working in small- or medium-sized hospitals.

The scale comprised 20 questions about nursing-record performance. Each appraiser randomly reviewed four records by written each participant, awarding 1 point for properly written records, and 0 for poorly written records. Each score evaluated for each record were summed up to the total score and total score ranges from 0 to 4 . The Cronbach's a was .79 in Kim's study [22] and .84 in this study.

Nursing record behavior

We assessed nursing record behavior using the nursing record behavior evaluation tool of Kim's study [22], and revised the sentence to fit the situation of small and medium hospitals. Our revisions were reviewed by the same experts listed as above. No major revision was required.

This tool comprised of 16 questions regarding nursing-record behavior, including the rules and principles for writing nursing records. Each appraiser observed participants as they wrote nursing records and rated their behavior on a five-point Likert scale from "Very poor" (1 point) to "Excellent" (5 points). The score ranges from 0 to 5 . Higher scores indicated excellent nursing-record behavior. The Cronbach's a was .92 in Kim's study [22] and .87 in this study.

\section{Development and Application of Nursing-Record Education Program}

To develop and education program on nursing record, we began by reviewing articles published in the last ten years, searching PubMed, CINAHL, the Korea Education and Research Information Service (KERIS), and the National Digital Science Library (NDSL). To determine our target group's educational needs, we conducted a preliminary investigation among 30 nurses working in small or medium hospitals in South Korea. The preliminary investigation revealed a high need for education on how to write nursing records and case-based education, particularly concerning documentation of doctors' orders and noncompliance, patients' reason for noncompliance, cases of defending medical malpractice, and nurse colleague's carelessness, and nursing records time. Through the preliminary investigation, the educational need for nursing records from a legal aspect of view was confirmed. The education program was developed by reviewing the literature on nursing records, standards of the Hospital Accreditation Program, and by reflecting the preliminary investigation results. Our education program's major topics included nursing-record guidelines and instructions and medico-legal case studies related to nursing records. The education program was reviewed by two directors of nursing departments, two head nurses with over 10 years of work experience in small- and medium-sized hospitals, and two professors from nursing college. The program was revised based on their feedback. The education program was a two-hour intensive workshop with reference to Kim's research results [22]. The workshop was conducted by researcher. The program consisted of lecture with PowerPoint presentation, discussions, interactive activities, and practical sessions. The researcher conducted the educational program once at each of the two hospitals, 16 participants per session. The participants received a 
hand out to enhance the information taught in the program. Team-based learning was carried out in groups of four to carry out tasks during education. Team-based learning was conducted to how to write related nursing record after outlining the medico-legal case. Table 1 summarizes the program's educational content.

\section{Data Collection}

We collected data between September 17th 28th, 2018. Before the pretest investigation, the researchers visited the hospitals and were given permission for this research by the nursing department. We selected nine nurse managers as appraisers, explained the purpose and goal of this study, and received their consent. And then, we explained the research process, measurement tools, and evaluation methods for 40 minutes. Training included a lecture and practice using the tool. In order to maintain consistency in evaluation among appraisers, evaluation practice was conducted using some nursing records as an example. At the end of training, feedback was given by researcher.

After data collection from control group, data collection from experimental group was carried out to prevent contamination. Data collection began after explaining to the participants the purpose and method of this study and receiving their written consent. A researcher distributed the questionnaire for sociodemographic data and knowledge of nursing records of participants at the baseline and had the participants fill out it on their own. The mean time of questionnaire completion was 20 minutes. Nursing record performance and behavior were evaluated by trained appraisers. The appraisers reviewed and evaluated four nursing records written by participants in a week. Also, they observed and evaluated a participant by the questionnaire on the nursing record behaviors.

Educational program was conducted once at each of the two hospitals. A total of 32 people, 16 participants per session were educated. Each program held in a hospital's meeting room for two hours. After the education program, we conducted the posttest investigations into knowledge of nursing records, nursing record performance and nursing record behaviors of the experimental group in the same way as baseline assessment. Data were collected from both groups using the same procedure.

\section{Statistical Analysis}

We analyzed the data using SPSS software (version 25.0, SPSS, Chicago, IL, USA). We performed a descriptive analysis for the participants' general characteristics, knowledge, performance,

Table 1. The Contents of Nursing Education Program

\begin{tabular}{|c|c|c|c|c|}
\hline Topic & Contents & $\begin{array}{l}\text { Teaching } \\
\text { methods }\end{array}$ & Material & $\begin{array}{l}\text { Time } \\
(\min )\end{array}$ \\
\hline Introduction & $\begin{array}{l}\text { - Social issues and policy changes } \\
\text { - Revised medical laws }\end{array}$ & Lecture & $\begin{array}{l}\text { PPT } \\
\text { Video clip }\end{array}$ & 10 \\
\hline $\begin{array}{l}\text { The method of writing } \\
\text { nursing records }\end{array}$ & $\begin{array}{l}\text { - Definition and purpose of nursing records } \\
\text { - General principles of nursing records } \\
\text { - Types and methods of writing nursing records }\end{array}$ & Lecture & PPT & 25 \\
\hline $\begin{array}{l}\text { Guidelines for writing } \\
\text { nursing records }\end{array}$ & $\begin{array}{l}\text { - Subject of records, timing of records, content of records, } \\
\text { method of records, content of not to be recorded } \\
\text { - Answer to measurement of nursing records knowledge }\end{array}$ & $\begin{array}{l}\text { Lecture } \\
\text { Q\&A }\end{array}$ & PPT & 25 \\
\hline Practice of nursing record & $\begin{array}{l}\text { - Filling initial information in an admission note and } \\
\text { nursing record } \\
\text { - Evaluation }\end{array}$ & $\begin{array}{l}\text { Practice } \\
\text { Discussion } \\
\text { Team based } \\
\text { learning }\end{array}$ & $\begin{array}{l}\text { Handout } \\
\text { Video clip }\end{array}$ & 15 \\
\hline $\begin{array}{l}\text { Nurses and nursing records } \\
\text { from a legal point of view }\end{array}$ & $\begin{array}{l}\text { - Position and duty of nurses from a legal point of view } \\
\text { - Conventions and cases related to nursing records }\end{array}$ & Lecture & $\begin{array}{l}\text { PPT } \\
\text { Video clip }\end{array}$ & 15 \\
\hline Discussing \& Role play & $\begin{array}{l}\text { - Case analysis of invalid medical records } \\
\text { - Conventions and cases related to nursing records }\end{array}$ & $\begin{array}{l}\text { Discussion } \\
\text { Team based } \\
\text { learning }\end{array}$ & $\begin{array}{l}\text { Handout } \\
\text { PPT } \\
\text { Video clip }\end{array}$ & 20 \\
\hline Summary \& Evaluation & $\begin{array}{l}\text { - Summary } \\
\text { - Question and answer }\end{array}$ & $\begin{array}{l}\text { Discussion } \\
\text { Q\&A }\end{array}$ & & 10 \\
\hline
\end{tabular}


and behaviors regarding nursing records. The $\mathrm{X}^{2}$-test and t-test were used to test the homogeneity of the general characteristics and dependent variables in the experimental and control groups. Independent $\mathrm{t}$-test was used to analyze the effect between two groups, the differences in the pretest and posttest for each group were analyzed using the paired t-test.

\section{Ethical Considerations}

This study was approved by the Institutional Review Board of Daegu Catholic University (CUIRB-2017-0089) to ensure the participants' bioethical treatment and safety. Permissions for research instruments were received from the owners of the research tools via email before their use.

Before starting the study, we explained to the participants the study's purpose and intent, informing them that they were not obliged to participate and they could withdraw from the study at any time, and that all personal information would be handled anonymously and confidentially, with the data discarded after the research was complete. All participants provided written consent to participate.

The participants received a small gift each time they participated. After the data collection process was complete, we provided educational materials to the control group participants if they want.

\section{Results}

\section{General Characteristics of Participants}

The 62 nurses participating were assigned to either the experimental $(n=32)$ or the control $(n=30)$ group. Among them, $38.7 \%$ were aged $26-30,54.8 \%$ had a bachelor's degree, $25.8 \%$ were married, $53.2 \%$ had worked for $1-5$ years, and $27.4 \%$ had worked for 5 years or more. Only 20 of the 62 nurses $(32.3 \%)$ had experience with education on nursing records. The experimental group did not statistically differ from the control group in general characteristics (Table 2).

\section{Preliminary Test of Homogeneity on Outcome Variables}

The preliminary test for homogeneity in the dependent variables for the control and experimental groups revealed the following. The nursing-record knowledge score was 53.09 \pm 5.83 in the experimental group and $50.90 \pm 6.09$ in the control group. The nursing-record performance scores were $3.39 \pm 0.34$ in the experimental group and $3.21 \pm 0.39$ in the control group. The nursing-record behavior scores were $3.97 \pm 0.34$ in the experimental group and $3.83 \pm 0.30$ in the control group. The test of homogeneity between the experimental and control groups showed no significant differences $(\mathrm{t}=1.45, \quad p=.153 ; \mathrm{t}=1.96$,

Table 2. Homogeneity of General Characteristics between Two Groups

\begin{tabular}{|c|c|c|c|c|c|c|}
\hline \multirow{2}{*}{ Characteristics } & \multirow[t]{2}{*}{ Categories } & Total & Exp. $(n=32)$ & Cont. $(n=30)$ & \multirow[t]{2}{*}{$x^{2}$} & \multirow{2}{*}{$p$} \\
\hline & & n (\%) & n (\%) & n (\%) & & \\
\hline \multirow{3}{*}{$\begin{array}{l}\text { Age } \\
\text { (year) }\end{array}$} & $\leq 25$ & $21(33.9)$ & $10(31.3)$ & $11(36.7)$ & \multirow[t]{3}{*}{1.62} & \multirow[t]{3}{*}{.444} \\
\hline & $26-30$ & $24(38.7)$ & $11(34.4)$ & $13(43.3)$ & & \\
\hline & $\geq 31$ & $17(27.4)$ & $11(34.4)$ & $6(20.0)$ & & \\
\hline \multirow[t]{2}{*}{ Level of education } & College & $28(45.2)$ & $13(40.6)$ & $15(50.0)$ & \multirow[t]{2}{*}{0.55} & \multirow[t]{2}{*}{.610} \\
\hline & University & $34(54.8)$ & $19(59.4)$ & $15(50.0)$ & & \\
\hline \multirow[t]{2}{*}{ Marital status } & Married & $16(25.8)$ & $11(35.3)$ & 5 (15.6) & \multirow[t]{2}{*}{2.53} & \multirow[t]{2}{*}{.150} \\
\hline & Unmarried & $46(74.2)$ & $21(64.7)$ & $25(84.4)$ & & \\
\hline \multirow{3}{*}{$\begin{array}{l}\text { Career in RN } \\
\text { (year) }\end{array}$} & $<1$ & $12(19.4)$ & $7(20.6)$ & $5(15.6)$ & \multirow[t]{3}{*}{0.36} & \multirow[t]{3}{*}{.863} \\
\hline & $1-5$ & $33(53.2)$ & $16(50.0)$ & $17(59.4)$ & & \\
\hline & $>5$ & $17(27.4)$ & $9(29.4)$ & $8(25.0)$ & & \\
\hline \multirow[t]{2}{*}{ Working unit } & GS & $33(53.2)$ & $16(50.0)$ & $17(56.7)$ & \multirow[t]{2}{*}{0.28} & \multirow[t]{2}{*}{.621} \\
\hline & NS & $29(46.8)$ & $16(50.0)$ & $13(43.3)$ & & \\
\hline \multirow{2}{*}{$\begin{array}{l}\text { Experience of nursing } \\
\text { record education }\end{array}$} & Yes & $20(32.3)$ & $12(37.5)$ & $8(26.7)$ & \multirow[t]{2}{*}{0.83} & \multirow[t]{2}{*}{.262} \\
\hline & No & $42(67.7)$ & $20(62.5)$ & $22(73.3)$ & & \\
\hline
\end{tabular}

Cont. $=$ control group; Exp.=experimental group; $\mathrm{RN}=$ registered nurse 
$p=.054 ; \mathrm{t}=1.73, p=.089)($ Table 3$)$.

\section{The Comparison of Nursing Record Knowledge, Nursing Record Performance, and Nursing Record Behavior between Two Groups}

Table 4 shows the mean values for nursing-record knowledge, performance, and behavior from the pretest and posttest. The experimental group's knowledge scores increased from $53.09 \pm 5.83$ to $59.44 \pm 3.14$ after the education program. The control group's scores increased slightly from $50.90 \pm 6.09$ to $54.17 \pm 6.14$. The difference between the two groups was statistically significant $(\mathrm{t}=2.43, p=.019)$.

The experimental group's performance scores increased from $3.39 \pm 0.34$ to $3.56 \pm 0.26$. The control group's scores dropped slightly from $3.21 \pm 0.39$ to $3.20 \pm 0.48$. The difference between the two groups was statistically significant $(\mathrm{t}=2.19, p=.033)$.

The experimental group's behavior scores increased from $3.97 \pm 0.34$ to $4.21 \pm 0.42$ after the education program. The control group's scores increased slightly from $3.83 \pm 0.30$ to $3.84 \pm 0.30$. The difference between the two groups was statistically significant $(\mathrm{t}=2.42, p=.018)$.

\section{Changes of Nursing Record Knowledge, Nursing Record Performance and Nursing Record Behavior in Experimental Group}

Table 5 shows the changes in the experimental group's scores after the education. The experimental group's scores in all areas improved after education. In the knowledge section, the correct answer rate for Do's increased from $0.89 \pm 0.10$ to $0.98 \pm 0.40$ ( $\mathrm{t}=5.48, p=.001)$, and the correct answer rate for Don'ts increased from $0.70 \pm 0.11$ to $0.80 \pm 0.08(\mathrm{t}=4.95, p=.001)$.

In the performance section, the most significant improvement was for "Record consistently in connection with the nursing process and records of previous workers," from $3.28 \pm 0.73$ to $3.63 \pm 0.49(\mathrm{t}=2.78, p=.009)$. The second was the item "Commit the results of physical assessment to an admission note" increased significantly from $3.39 \pm 0.50$ to $3.71 \pm 0.46 \quad(\mathrm{t}=3.10$, $p=.004)$.

In the behavior section, the most significant improvement was for "Record the doctor's call and communication during the call" from $3.75 \pm 0.84$ to $4.41 \pm 0.61 \quad(\mathrm{t}=4.98, p=.001)$. The second was the item "Do not record negative views about patients" increased significantly from $3.97 \pm 0.74$ to $4.56 \pm 0.56(\mathrm{t}=4.44, p=.001)$.

Table 3. Homogeneity of Dependent Variables between Two Groups

$(\mathrm{N}=62)$

\begin{tabular}{|c|c|c|c|}
\hline \multirow{2}{*}{ Variables } & \multirow{2}{*}{ Group } & Pre-test & \multirow{2}{*}{$\mathrm{t}(p)$} \\
\hline & & Mean \pm SD & \\
\hline \multirow{2}{*}{ Knowledge toward nursing record } & Exp. $(n=32)$ & $53.09 \pm 5.83$ & 1.45 \\
\hline & Cont. $(n=30)$ & $50.90 \pm 6.09$ & $(.153)$ \\
\hline \multirow{2}{*}{ Nursing record performance } & Exp. $(n=32)$ & $3.39 \pm 0.34$ & 1.96 \\
\hline & Cont. $(n=30)$ & $3.21 \pm 0.39$ & $(.054)$ \\
\hline \multirow{2}{*}{ Nursing record behavior } & Exp. $(n=32)$ & $3.97 \pm 0.34$ & 1.73 \\
\hline & Cont. $(n=30)$ & $3.83 \pm 0.30$ & $(.089)$ \\
\hline
\end{tabular}

Cont. $=$ control group; Exp.=experimental group

Table 4. The Comparison of Nursing Record Knowledge, Nursing Record Performance, and Nursing Record Behavior between Two Groups

\begin{tabular}{|c|c|c|c|c|c|}
\hline \multirow{2}{*}{ Variables } & \multirow{2}{*}{ Group } & Pre-test & Post-test & Difference & \multirow{2}{*}{$\mathrm{t}(p)$} \\
\hline & & Mean \pm SD & Mean $\pm S D$ & Mean \pm SD & \\
\hline \multirow{2}{*}{ Knowledge toward nursing record } & Exp. $(n=32)$ & $53.09 \pm 5.83$ & $59.44 \pm 3.14$ & $6.35 \pm 6.22$ & \multirow{2}{*}{$\begin{array}{c}2.43 \\
(.019)\end{array}$} \\
\hline & Cont. $(n=30)$ & $50.90 \pm 6.09$ & $54.17 \pm 6.14$ & $3.27 \pm 3.45$ & \\
\hline \multirow{2}{*}{ Nursing record performance } & Exp. $(n=32)$ & $3.39 \pm 0.34$ & $3.56 \pm 0.26$ & $0.17 \pm 0.08$ & \multirow{2}{*}{$\begin{array}{c}2.19 \\
(.033)\end{array}$} \\
\hline & Cont. $(n=30)$ & $3.21 \pm 0.39$ & $3.20 \pm 0.48$ & $0.01 \pm 0.09$ & \\
\hline \multirow{2}{*}{ Nursing record behavior } & Exp. $(n=32)$ & $3.97 \pm 0.34$ & $4.21 \pm 0.42$ & $0.24 \pm 0.08$ & \multirow{2}{*}{$\begin{array}{c}2.42 \\
(.018)\end{array}$} \\
\hline & Cont. $(n=30)$ & $3.83 \pm 0.30$ & $3.84 \pm 0.36$ & $0.01 \pm 0.06$ & \\
\hline
\end{tabular}

Cont.=control group; Exp.=experimental group 
Table 5. Changes of Nursing Record Knowledge, Nursing Record Performance, and Nursing Record Behavior in Experimental Group

$(\mathrm{N}=32)$

\begin{tabular}{|c|c|c|c|c|}
\hline \multirow{3}{*}{ Questions } & \multicolumn{4}{|c|}{ Experimental group } \\
\hline & Pre-test & Post-test & Difference & \multirow{2}{*}{$\mathrm{t}(p)$} \\
\hline & \multicolumn{3}{|c|}{ Mean $\pm S D$} & \\
\hline \multicolumn{5}{|l|}{ Knowledge toward nursing record } \\
\hline Do’s & $0.89 \pm 0.10$ & $0.98 \pm 0.04$ & $0.09 \pm 0.06$ & $5.48(.001)$ \\
\hline Don'ts & $0.70 \pm 0.11$ & $0.80 \pm 0.08$ & $0.10 \pm 0.03$ & $4.95(.001)$ \\
\hline \multicolumn{5}{|l|}{ Nursing record performance } \\
\hline Commit initial information to an admission note. & $3.14 \pm 0.85$ & $3.46 \pm 0.79$ & $0.32 \pm 0.06$ & $1.97(.059)$ \\
\hline Commit the results of physical assessment to an admission note. & $3.39 \pm 0.50$ & $3.71 \pm 0.46$ & $0.32 \pm 0.04$ & $3.10(.004)$ \\
\hline $\begin{array}{l}\text { Perform the fall down assessment at the appointed time and record the } \\
\text { results. }\end{array}$ & $3.63 \pm 0.66$ & $3.66 \pm 0.65$ & $0.03 \pm 0.01$ & $0.44(.662)$ \\
\hline Perform the pain assessment at the appointed time and record the results. & $3.69 \pm 0.47$ & $3.66 \pm 0.48$ & $-0.03 \pm 0.01$ & $0.37(.712)$ \\
\hline $\begin{array}{l}\text { Perform the bed sore assessment at the appointed time and record the } \\
\text { results. }\end{array}$ & $3.34 \pm 0.87$ & $3.34 \pm 0.87$ & $0.00 \pm 0.00$ & $0.00(1.000)$ \\
\hline Record the information on transfusion in accordance with the guidelines. & $4.00 \pm 0.00$ & $3.86 \pm 0.38$ & $-0.14 \pm 0.38$ & $1.00(.356)$ \\
\hline Do not omit the signature of the medication, sign the administration record. & $3.71 \pm 0.53$ & $3.81 \pm 0.40$ & $0.10 \pm 0.13$ & $0.09(.374)$ \\
\hline Do not omit the signature and record for nursing care. & $3.39 \pm 0.56$ & $3.61 \pm 0.50$ & $0.23 \pm 0.06$ & $2.53(.017)$ \\
\hline Record all nursing activities and results related vital signs measurement & $3.32 \pm 0.79$ & $3.65 \pm 0.61$ & $0.32 \pm 0.18$ & $2.56(.016)$ \\
\hline Record observations and measurements accurately. & $3.34 \pm 0.77$ & $3.52 \pm 0.78$ & $0.17 \pm 0.02$ & $2.42(.023)$ \\
\hline Record the nursing process in order without omission. & $3.29 \pm 0.86$ & $3.39 \pm 0.80$ & $0.10 \pm 0.06$ & $0.72(.476)$ \\
\hline Select and record a suitable nursing diagnosis. & $3.11 \pm 0.93$ & $3.37 \pm 0.79$ & $0.26 \pm 0.14$ & $1.32(.199)$ \\
\hline $\begin{array}{l}\text { Select and record the necessary a nursing intervention in compliance with a } \\
\text { nursing diagnosis. }\end{array}$ & $3.09 \pm 0.78$ & $3.38 \pm 0.79$ & $0.28 \pm 0.02$ & $1.66(.107)$ \\
\hline Record the evaluation of the results after nursing intervention. & $3.16 \pm 0.88$ & $3.41 \pm 0.76$ & $0.25 \pm 0.13$ & $1.31(.199)$ \\
\hline $\begin{array}{l}\text { Record consistently in connection with the nursing process and records of } \\
\text { previous workers }\end{array}$ & $3.28 \pm 0.73$ & $3.63 \pm 0.49$ & $0.34 \pm 0.24$ & $2.78(.009)$ \\
\hline Record the training on precautions when leaving the hospital. & $3.15 \pm 0.83$ & $3.54 \pm 0.71$ & $0.38 \pm 0.13$ & $1.92(.067)$ \\
\hline $\begin{array}{l}\text { Minimize the use of abbreviations and use only standardized abbreviations } \\
\text { if necessary. }\end{array}$ & $3.42 \pm 0.72$ & $3.58 \pm 0.56$ & $0.16 \pm 0.16$ & $1.22(.231)$ \\
\hline Record spell or grammar correctly. & $3.59 \pm 0.50$ & $3.56 \pm 0.50$ & $-0.03 \pm 0.01$ & $0.37(.712)$ \\
\hline Do not write using slang or inappropriate terms. & $3.75 \pm 0.51$ & $3.88 \pm 0.34$ & $0.13 \pm 0.17$ & $1.44(.161)$ \\
\hline When referring to other employees, record the name and occupation. & $2.95 \pm 1.08$ & $3.47 \pm 0.70$ & $0.53 \pm 0.38$ & $1.96(.066)$ \\
\hline \multicolumn{5}{|l|}{ Nursing record behavior } \\
\hline Login only with your ID & $4.47 \pm 0.57$ & $4.44 \pm 0.62$ & $-0.03 \pm 0.05$ & $0.30(768)$ \\
\hline If you need to correct record, only correct your record. & $4.22 \pm 0.71$ & $4.13 \pm 0.75$ & $-0.09 \pm 0.04$ & $0.59(.690)$ \\
\hline After nursing treatment, write in a nurse's note. & $4.13 \pm 0.83$ & $4.06 \pm 0.76$ & $-0.06 \pm 0.07$ & $0.40(.690)$ \\
\hline After the medication, sign the administration record. & $3.81 \pm 0.90$ & $4.06 \pm 0.88$ & $0.25 \pm 0.02$ & $1.68(.103)$ \\
\hline After a treatment, sign the nursing care activity chart. & $3.94 \pm 0.72$ & $4.19 \pm 0.78$ & $0.25 \pm 0.06$ & $1.68(.103)$ \\
\hline Record only direct observations, measurements and count. & $3.91 \pm 0.64$ & $4.09 \pm 0.69$ & $0.19 \pm 0.05$ & $1.29(.206)$ \\
\hline Record the doctor's call and communication during the call. & $3.75 \pm 0.84$ & $4.41 \pm 0.61$ & $0.66 \pm 0.23$ & $4.98(.001)$ \\
\hline Record caregiver's remarks related to information about cares. & $3.75 \pm 0.76$ & $3.72 \pm 0.77$ & $-0.03 \pm 0.01$ & $0.16(.872)$ \\
\hline Record the patient's appeal without omission. & $3.72 \pm 0.85$ & $4.13 \pm 0.55$ & $0.41 \pm 0.30$ & $2.14(.040)$ \\
\hline Record the nursing actions about the patient's appeal without omission. & $3.88 \pm 0.94$ & $4.31 \pm 0.78$ & $0.44 \pm 0.16$ & $2.95(.006)$ \\
\hline Record the patient's nonfulfillment. & $3.66 \pm 0.55$ & $3.91 \pm 0.69$ & $0.25 \pm 0.14$ & $1.97(.058)$ \\
\hline Record the size and amount after quantifying them, if possible. & $3.97 \pm 0.90$ & $4.16 \pm 0.63$ & $0.19 \pm 0.27$ & $1.14(.263)$ \\
\hline Record the flow of context so that nonmedical persons can see it. & $3.94 \pm 0.72$ & $4.31 \pm 0.59$ & $0.38 \pm 0.12$ & $2.83(.008)$ \\
\hline Do not record the nurse's subjective judgment on a patient. & $4.13 \pm 0.91$ & $4.44 \pm 0.72$ & $0.31 \pm 0.19$ & $1.90(.067)$ \\
\hline Do not record negative expressions about patients & $4.28 \pm 0.68$ & $4.47 \pm 0.62$ & $0.19 \pm 0.06$ & $1.98(.056)$ \\
\hline Do not record negative views about patients. & $3.97 \pm 0.74$ & $4.56 \pm 0.56$ & $0.59 \pm 0.18$ & $4.44(.001)$ \\
\hline
\end{tabular}




\section{Discussion}

This study was conducted to evaluate the effects of a nursing record education program on nurses' knowledge and performance on nursing records in small and medium hospitals in South Korea.

$32.3 \%$ of the participants had received education on nursing records at their hospitals. This result was similar to the findings of Goo [23], who measured knowledge level about nursing records of clinical nurses in general hospital and clinic and found that $32.2 \%$ had previously received education on nursing records. Both Goo's study [23] and this study, where the participants were nurses in small and medium-sized hospitals, showed that the subjects did not have much educational experience in nursing records. Lee et al. [12] reported that over $70 \%$ of nurses in large hospitals received education on nursing records, meaning that nurses who work at small- and medium-sized hospitals have fewer opportunities to receive education on nursing records compared with those who work in large hospitals.

The experimental group that received nursing record education scored higher on the knowledge of nursing records compared with the control group that did not receive the education. This result was consistent with both studies of Kim \& Yi [19] and Kim et al. [24] that nurses' nursing record knowledge improved after an educational intervention. The experimental group's correct answer rate for Do's section of nursing record increased from 0.89 to 0.98 , and its correct answer rate for Don'ts increased from 0.70 to 0.80 . This result was consistent with the finding of Kim et al. [24] which showed improvements of 0.86 to 0.90 and 0.75 to 0.90 , respectively. In this study, nursing-record knowledge did not improve as much as it did in other studies. This seems to be due to insufficient education hours. Therefore, it will be necessary to choose the educational environment, methods, and sufficient hours considering the target audience.

It has been shown that there is a lack of knowledge about the legal aspects of nursing records. This result was consistent with the finding of Lee et al. that only $70 \%$ of nurses correctly answered questions on the same items [12]. Kim [14] reported that nurses lacked awareness about medico-legal disputes and attributed to be due to lack of proper education on nursing records' legal aspects. Several studies have examined the importance of nursing records. Kim \& Yi [19] found the benefits of nursing-record education focused on the legal aspects, as did the study of Kim et al. [24] that $83.3 \%$ of nurses said that nursing-record education focusing on the legal aspects is necessary. Nursing-record education should include medical law, which is frequently revised, and information about trial cases related to nursing malpractice incidents. An online education program on the legal aspects of nursing records could effectively help educate nurses, including those at small and medium hospitals who have fewer opportunities for education while also providing them sufficient time to study [25].

The experimental group scored higher on nursing-record performance than the control group. This was consistent with the study of Linch et al. [26] reported that the quality of nursing records among nurses in the coronary care unit increased after an educational intervention. Our experimental group's nursing-record performance scores increased from 3.39 to 3.56 out of 4 . Although different assessment tools were used, this increase was higher than the $62 \%$ reported by Lee [6] and similar to the $82 \%$ reported by Kang [7]. The reasons for this result are not clear; however, it seems to be attributed to the fact that the participant's hospitals manage nursing records according to hospital accreditation standards [17].

In more detail, the experimental group's performance scores for five performances-related items improved after education. However, the scores did not improve for the items on recording the nursing process and the results of nursing interventions. Establishing an appropriate nursing process can improve the quality of nursing records and increase communication between medical staff, consequently bringing positive outcomes for patients [26]. However, ENRs use standardized terminologies about nursing diagnoses and interventions that do not always sufficiently describe patients' situations and nursing processes [27]. It is necessary to update the ENR database on diagnoses and interventions regularly to improve their nursing record performance.

The experimental group's nursing-record behavior scores increased more significant than those of the control group, this result was consistent with Kim's study [22] showing that nurses' nursing record behavior in large hospitals improved after an educational intervention. But, some legally sensitive items did not improve significantly after the intervention such as: "Management of your own ID related to nursing record". These items are very sensitive parts from a legal perspective. There have been many legal suits related to cases in which the nurse did not record the nursing care for his or her conduct. From a 
legal standpoint, the nurse who treated the patient is recognized as the recorder of the medical record, so the nursing record must be completed by that nurse only. This result suggests the need for additional training about legal aspects of nursing records.

In the study results, there were items that were not performed even though the knowledge score was high. Kim \& Yi [19] reported similar results when they compared general hospital nurses' post-education improvements in nursing record knowledge and performance. Kang [7] reported that nurses recorded only $52 \%$ of the nursing activities that they performed. Similarly, Mykkänen et al. [28] found that some nurses did not record their nursing activities-although they knew it was mandatory-citing reasons such as lack of time, overload, and nurse's tendency to prioritizing direct nursing care over record keeping. From a legal standpoint, undocumented nursing care is considered as never having been given. Therefore, nurses must be regularly educated to grow more aware of how important it is to record comprehensively and accurately recording all nursing activities. Monitoring their recording should be routine to ensure compliance. Nurses must realize that maintaining nursing records is an integral part of nursing care that allows medical staff to precisely understand patients' conditions [8,29].

Based on these results, more effective education strategies and programs must be developed to raise the awareness about the importance of nursing records and improve nurses' performance as well as knowledge to writing nursing records. New nurses who receive nursing-record education perform better at record keeping than those who do not [17]. This suggests that it would be a more efficient way to include how to write nursing record for new employee's education. It was also found that nurses' performance increased when both lectures and hands-on training were provided. Thus, hands-on training on writing nursing records in various clinical situations, in addition to regular lectures, will effectively enhance nurses' knowledge and performance to writing nursing records. Additionally, to increase the quality of nursing records and maintain the improved quality, consistent monitoring and repeated education on nursing records at the nursing department level are necessary.

A study reported that education on topics nurses consider important or are interested was highly effective in maintaining nurses' performance for a long time [30]. In a sense, nursing record education in the legal aspect can prepare for unexpected legal disputes in the nursing field, and it is necessary to emphasize the importance of nursing record in the legal aspect, especially for nurses at small and medium sized hospitals relatively many medical litigation. Additionally, to increase and maintain nursing-record quality requires consistent monitoring and continuing education at the department level.

In this study, we found that nursing-record education improved nurses' knowledge and performance in writing nursing records in small and medium sized hospitals in South Korea. In particular, it was found that the legal aspect of nursing records should be more important and education on them is necessary. In addition, this result is especially meaningful in that it objectively assessed the effect of the education program by using third-party evaluation instead of self-reported questionnaires.

The study has various limitations: The recruitment of participants was only from two hospitals, the results could not be inferred to all nurses. In addition, the post-test was conducted only once, the lasting effect could not be confirmed. Further research may track longer periods to validate measurement results.

\section{Conclusion}

In this study, nurses' nursing record knowledge, performance, and behavior improved significantly after nursing record education. Based on this result, nursing record education is an effective intervention to improve nurses' knowledge and performance to writing nursing records in small- and medium sized hospitals. We suggest the development of a systematic and standardized education program on nursing records included its legal aspect for nurses in small- and medium sized hospitals. The results would be helpful as basic data for developing a nursing record education program for nurses in small and medium sized hospitals.

\section{Conflict of interest}

No potential conflict of interest relevant to this article was reported.

\section{Funding}

None 


\section{Acknowledgements}

None

\section{Supplementary materials}

None

\section{References}

1. Griffith R. What to include in a nursing record. British Journal of Nursing. 2016;25(9):520-521. https://doi.org/10.12968/ bjon.2016.25.9.520

2. Cho IS, Choi WJ, Choi WH, Kim MK. The adoptions and use of electronic nursing records in Korean hospitals: findings of a nationwide survey. Journal of Korean Clinical Nursing Research. 2013;19(3):345-356. https://doi.org/10. 22650/JKCNR.2013.19.3.345

3. Whittenburg L, Meetim A. Electronic nursing documentation: patient care continuity using the clinical care classification system (CCC). Studies in Health Technology and Informatics. 2016;225:13-17. https://doi.org/10.3233/978-161499-658-3-13

4. Inan NK, Dinç L. Evaluation of nursing documentation on patient hygienic care. International Journal of Nursing Practice. 2013;19(1):81-87. https://doi.org/10.1111/ijn.12030

5. Vankipuram M, Kahol K, Cohen T, Patel VL. Toward automated workflow analysis and visualization in clinical environments. Journal of Biomedical Informatics. 2011;44(3): $432-440$.

6. Lee JY. Analysis of factors to complete nursing documentation through initial nursing assessment record [master's thesis]. Seoul: Yonsei University; 2017. p. 1-50.

7. Kang MM. Comparison of the performance and the record of nursing behaviors using the INCP in ICU [master's thesis]. Gyeonggi-do: Dankook University; 2006. p. 1-65.

8. Gomes DC, Cubas MR, Pleis LE, Shmeil MA, Peluci AP. Terms used by nurses in the documentation of patient progress. Revista Gaúcha de Enfermagem. 2016;37(1): e53927. https://doi.org/10.1590/1983-1447.2016.01.53927

9. Ehrenberg A, Ehnfors M. The accuracy of patient records in Swedish nursing homes: congruence of record content and nurses' and patients' descriptions. Scandinavian Journal of Caring Science. 2001;15(4):303-310. https://doi.org/10.1046/ j.1471-6712.2001.00044.x

10. Hwang ES, Lee SJ, Kim SJ, Heo IH. A study on knowledge, importance and performance in nursing records of university hospital nurses. Journal of Korean Critical Care Nursing. 2019;12(1):71-81.

11. Selvi ST. Documentation in nursing practice. International Journal of Nursing Education. 2017;9(4):121-123. https://oi.org/ 10.5958/0974-9357.2017.00108.8

12. Lee SM, Yoon SY, Kwon SY. A study on the knowledge level of nursing documentation among nurse officers in military hospitals: focusing on the legal aspects. Journal of Military Nursing Research. 2013;31(2):118-128.

13. Jung EY, Yang SH. A study on the knowledge level of nursing records among nursing students-focusing on legal aspects. Journal of East-West Nursing Research. 2017;23(2): 150-159. https://doi.org/10.14370/jewnr.2017.23.2.54

14. Kim YM. Development and evaluation of an educational program on legal issue-focused nursing records. Journal of Korean Clinical Nursing Research. 2013;19(3):369-382.

15. Korea Medical Dispute Mediation and Arbitration Agency. Medical dispute mediation and arbitration statistical yearbook 2019. Seoul: Korea Medical Dispute Mediation and Arbitration Agency; 2020.

16. National Health Insurance Service. National health insurance service statistical year book 2019 [Internet]. Gangwon: National Health Insurance Service; 2020 [cited 2021 Feb 14]. Available from: https://www.nhis.or.kr/nhis/together/wbhaec 06300m01.do?mode $=$ view\&articleNo $=10802543 \&$ article.offset $=0$ \&articleLimit $=10$

17. Kang HS, Song HJ. The association between safety care activity and documentation of nursing records among nurses in general hospitals. Journal of Korean Critical Care Nursing. 2018;11(3):85-94.

18. Jung MJ. Study on the needs, accommodation and satisfaction toward the nursing practice program of the nurses in small to medium sized hospitals [master's thesis]. Gwangju: Nambu University; 2012. p. 1-59.

19. Kim EY, Yi YJ. Effects on knowledge and performance in clinical nursing of education on nursing recording focusing on legal aspects. Journal of Korean Academic Nursing Administration. 2011;17(3):277-283. https://doi.org/10.11111/ jkana.2011.17.3.277

20. Faul F, Erdfelder E, Lang AG, Buchner A. G*Power 3: a flexible statistical power analysis program for the social, 
behavioral, and biomedical sciences. Behavior Research Methods. 2007;39(2):175-191. https://doi.org/10.3758/bf03193146

21. Kim YM, Park SA. A nurse charting knowledge scale: focusing on legal aspects. Journal of Korean Clinical Nursing Research. 2007;13(2):27-38.

22. Kim YM. Development and evaluation of an educational program on legal issue-focused nursing records. Journal of Korean Clinical Nursing Research. 2013;19(3):369-382.

23. Goo KH. The level of clinical nurses' knowledge about how to write nursing records [master's thesis]. Daegu: Kyungpook National University; 2012. p. 1-38.

24. Kim N, Park Y, Lee Y, Yang Y. Effects of nursing recording education focusing the legal aspects on the nurses' knowledge, confidence and education satisfaction in a local hospital. Asian Pacific Journal of Multimedia Services Convergent with Art Humanities and Sociology. 2019; 9(12):509-522. https://doi.org/10.35873/ajmahs.2019.9.12.046

25. Eun Y, Kang HS, Jeon MY. Survey on online continuing education requirements according to practical experience of nurses at small and medium sized hospitals. Journal of Muscle Joint Health. 2016;23(3):197-205. https://doi.org/10.5953/ jmjh.2016.23.3.197

26. Linch GFDC, Lima AAA, Souza EN, Nauderer TM, Paz
AA, da Costa C. An educational intervention impact on the quality of nursing records. Revista Latino-Americana de Enfermagem. 2017;30(25):e2938. https://doi.org/10.1590/1518 $-8345.1986 .2938$

27. Ahn JO, Jung YM, Cha JH, Lee HJ, Lee SY. Nurses' perception on EMR and standardized nursing statements in Korea armed forces hospitals. Journal of Military Nursing Research. 2018;36(1):71-83. https://doi.org/10.31148/kjmnr. 2018.36.1.71

28. Mykkänen M, Miettinen M, Saranto K. Standardized nursing documentation supports evidence-based nursing management. Studies in Health Technology and Informatics. 2016;225:466 -470 .

29. Jefferies D, Johnson M, Griffiths R. A meta-study of the essentials of quality nursing documentation. International Journal of Nursing Practice. 2010;16:112-124. https://doi.org/ 10.1111/j.1440-172x.2009.01815.x

30. Jang SJ, Lee HO, Kwon JH, Lee SH. The effects of safe handling education of antineoplastic drug on knowledge and performance of clinical nurses. Journal of Korean Clinical Nursing Research. 2016;22(2):217-224. https://doi.org/10. 22650/JKCNR.2016.22.2.217 